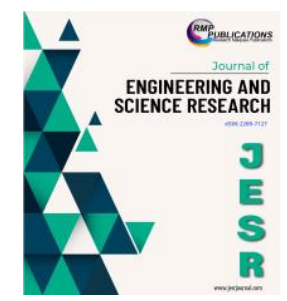

\title{
Effect of Silver and Tin on the Corrosion Behaviour of Zinc Alloy in Alkaline Medium
}

\author{
Hadi Purwanto ${ }^{1}$, Hanisah Manshor ${ }^{1}$ and Farihan M. Azizan ${ }^{2}$ \\ ${ }^{1}$ Faculty of Engineering, International Islamic University Malaysia, Jalan Gombak Kuala Lumpur, \\ Malaysia. \\ ${ }^{2}$ Former Research officer at Royal Selangor International Sdn. Bhd, Malaysia.
}

\begin{abstract}
The electrochemical and corrosion behaviour of $\mathrm{Zn}-20 \mathrm{Sn}$ and $\mathrm{Zn}-0.50 \mathrm{Ag}$ alloys in dishwasher detergent solution was investigated by Tafel plot and characterized X-ray diffraction (XRD) and Scanning Electrode Microscope (SEM). The measurements were conducted using different composition of elements addition (Ag: $0.03 \%, 0.27 \%$ and $0.50 \%$. Sn: $1 \%, 8 \%$, and $15 \%$ ) under the same experimental conditions. The results showed that the addition of $\mathrm{Ag}$ led to decreased corrosion rate compared to Sn addition. The corrosion potential for $\mathrm{Zn}$ alloy with Ag addition are shifted towards more noble values compared to $\mathrm{Zn}$ alloys with $\mathrm{Sn}$ addition . By adding Ag, the current density is decreased and thus reducing the hydrogen evolution rate. The corrosion layer formed on Zinc sample in dishwasher detergent was investigated. The corrosion layer formed on $\mathrm{Zn}-20 \mathrm{Sn}-0.5 \mathrm{Ag}$ appeared more compact than other alloys. Zinc oxide $(\mathrm{ZnO})$ and $\mathrm{Zinc}$ hydroxide $\left(\mathrm{Zn}(\mathrm{OH})_{2}\right)$ were formed on Zinc alloy surface. Probable mechanisms of Zinc corrosion products formation are presented.
\end{abstract}

Key words: Corrosion, zinc alloy, silver, tin, giftware, electrochemical, alkaline solution.

\section{INTRODUCTION}

Pewter alloy has long been used in the giftware industry to produce products such as tableware and dishware. However, the current price of the main element of pewter which is tin continues to rise and leads to high production costs. $\mathrm{Zn}$ alloys have been proposed to be a substitute for the pewter alloy because they have similar mechanical properties. A $\mathrm{Zn}$ alloy is one of the promising alternatives for Pewter alloy because of its low melting temperature. Other great advantages of the $\mathrm{Zn}$ alloy are its low cost and excellent mechanical properties, but it is susceptible to oxidation and corrosion ([1][2][3][4]).

The dishwasher detergent is a special detergent used to wash and clean the pewter-giftware products. The same cleaning method is applied for the alternative zinc alloy. The application of the dishwasher detergent on zinc alloy might produce stains and expose the metal to corrosive environments. Corrosion resistance is an important parameter for the choice of $\mathrm{Zn}$ alloys. Takemoto et. al. [5] established that the addition of Ag to the $\mathrm{Zn}$ alloy inhibits the anodic dissolution of zinc and enhances corrosion resistance. It has been shown that alloying $\mathrm{Ag}$ can slow down the corrosion rate and promote growth of the compact passive layer. However, the addition of $\mathrm{Ag}$ induces an increase of the melting point. Melting temperature is also an important characteristic for the development of $\mathrm{Zn}$ alloys. The addition of $\mathrm{Sn}$ to $\mathrm{Zn}$ alloy was found to provide a slight reduction of the melting temperature [6]. An Sn addition up to $20 \%$ to the $\mathrm{Zn}$ alloy reduced the melting point and improved the oxidation resistance.

$\mathrm{Zn}$ corrosion in alkaline solution is cathodic controlled, so the rate of the cathodic hydrogen evolution limits the $\mathrm{Zn}$ corrosion rate. Hence, the best way to slow down the corrosion process is to reduce the hydrogen evolution rate, which can be achieved by the introduction of a small amount of other metals (Ag and $\mathrm{Sn}$ into $\mathrm{Zn}$ alloy) $[7,8]$.

However, there is a lack of information on the electrochemical corrosion behavior of ternary $\mathrm{Zn}-\mathrm{Ag}$ Sn alloy in dishwasher detergent solution. Lower corrosion resistance is representative of a lower current conductive effect and reduces the lifetime and appearance of the giftware product. This paper

Corresponding Author: Hadi Purwanto, Faculty of Engineering, International Islamic University Malaysia, Jalan Gombak Kuala Lumpur, Malaysia, 03-6197-5753 
provides detailed information about the electrochemical behavior of zinc alloys. The objective of this work is to get more knowledge about the electrochemical and corrosion behavior of $\mathrm{Zn}-\mathrm{Ag}-\mathrm{Sn}$ alloy. Furthermore, the aim of this work is also to examine the effect of adding $\mathrm{Ag}$ and $\mathrm{Sn}$ as alloying elements on the corrosion of $\mathrm{Zn}$.

\section{EXPERIMENT}

\section{Materials and Solution Preparation}

$\mathrm{Zn}-20 \mathrm{Sn}$ alloys with $\mathrm{Ag}$ addition $(0.03 \%, 0.27 \%$ and $0.50 \%)$ and $\mathrm{Zn}-0.50 \mathrm{Ag}$ alloys with different $\mathrm{Sn}$ addition $(1 \%, 8 \%$, and $15 \%)$ were prepared by being melted in a crucible at $420{ }^{\circ} \mathrm{C}$ and casted. Zn alloy samples were cut from the prepared $\mathrm{Zn}$ alloys. The sample size was 10 $\mathrm{mm} \times 10 \mathrm{~mm}$ × $2 \mathrm{~mm}$. Samples were encapsulated in resin and only one surface was exposed to the solution. This approach facilitated the examination of corrosion morphology. Prior to studies, each sample surface was mechanically abraded using emery paper in successive grades from 300 to 1200 and mirror polished with the use of $1-0.05 \mu \mathrm{m}$ diamond paste. Samples were finally degreased with ethanol, ultrasonically rinsed with distilled water and dried. The electrolyte used to investigate the corrosion behavior of $\mathrm{Zn}$ alloy was a special dishwasher detergent with $\mathrm{pH}$ 13.6. A commercial dishwasher detergent was commonly used as a cleaning solution for the raw giftware product. This solution was used in order to facilitate the interpretation of the corrosion behavior observed in alkaline solution.

\section{Electrochemical Test}

The electrochemical test was performed on five samples of each alloy in a glass beaker. A three-electrode cell was used for the electrochemical studies. Platinum wire was used as the counter electrode (CE) with saturated calomel electrode (SCE) as reference electrode. The Zn sample was used as a working electrode. The electrochemical measurements were conducted using a PGSTAT302N Autolab potentiostat coupled with GPES software. The test was started immediately after the working electrode connected to the cell and the electrolyte was poured. The electrodes were kept immersed in the electrolyte. Tafel extrapolation technique was used to measure the corrosion rate, corrosion potential and current density. The extrapolation of anodic and cathodic Tafel lines was carried out in a potential range $\pm 1 \mathrm{~V}$ with respect to corrosion potential (Ecorr) at a scan rate of $0.01 \mathrm{~V} / \mathrm{s}$ and step potential of $0.00106 \mathrm{~V}$.

\section{Characterization}

To investigate the relationship between the alloying elements and the surface morphology, the surface was characterized using Scanning Electron Microscope (SEM) and X-Ray Diffraction (XRD) techniques. XRD measurements were performed using XRD-6000 Shimadzu diffractometer equipped with secondary monochromator and with a $\mathrm{Cu}$ radiation source. The XRD patterns were recorded in a continuous scanning mode. The $2 \theta$ range was recorded at scan speed of $2^{\circ}$ $\min ^{-1}$ with $0.02^{\circ}$ step. A scanning electron microscopy (JEOL JSM-5600) was used for the surface characterizations to examine the surface morphologies.

\section{RESULT AND DISCUSSION}

\section{Polarization Behavior}

The polarization studies provide further understanding of the corrosion behavior of the corresponding alloys. Fig. 1 shows the comparison of polarization curves of $\mathrm{Zn}$-20Sn alloys, with Ag contents of $0.03,0.27$ and 0.50 wt.\%. Corrosion parameters were calculated based on cathodic and anodic potential vs current density characteristics in the Tafel potential region $[9,10]$. The values of the corrosion current density (Icorr) for reference alloy and $\mathrm{Zn}$-based alloys were determined by extrapolation of the cathodic and anodic Tafel lines to corrosion potential (Ecorr). Both cathodic and anodic branches on the polarization curves of Zn-based alloys were shifted towards lower current densities as the content of Ag increased. This indicates that the rates of oxygen reduction and anodic dissolution decrease with increasing Ag content [11]. Zn-20Sn alloy with $0.50 \mathrm{Ag}$ showed the lowest current densities while $\mathrm{Zn}-20 \mathrm{Sn}-0.03 \mathrm{Ag}$ showed the highest among all the alloys. A similar trend was observed between reference alloy and $\mathrm{Zn}-20 \mathrm{Sn}-0.50 \mathrm{Ag}$ alloy in the same concentration of alkaline solution. Thus, it can be suggested that alloy with addition of $0.50 \mathrm{wt} \% \mathrm{Ag}$ possesses similar characteristics to reference alloy. On the other hand, from the polarization curves, the corrosion potential (Ecorr) shifted positively with simultaneous addition of Ag content, indicating that the $\mathrm{Ag}$ addition increases the nobility and stability of $\mathrm{Zn}$ alloy approaching the corrosion potential of the reference alloy (Pewter). Zn-20Sn-0.03Ag shows the lowest corrosion potential value compared to other alloys. Although some studies mentioned the identification of the microgalvanic corrosion between the cathodic $\mathrm{Ag}_{3} \mathrm{Sn}$ compounds and the anodic $\mathrm{Zn}$ matrix [12,13], Cheng et al. reported that the Zn-rich phase disappear in the Sn matrix when 0.5 mass\% $\mathrm{Ag}$ was added to the Zn-20Sn alloy, which shows that the $\mathrm{Ag}$ addition increases the solubility of $\mathrm{Zn}$ in $\mathrm{Sn}$ matrix [14]. It can also be ascribed to the lower polarizing action of $\mathrm{Ag}_{3} \mathrm{Sn}$ phase since hydrogen overpotential on particles of $\mathrm{Ag}_{3} \mathrm{Sn}$ phase might be lower. In general, it is observed that the intermetallic compound promotes the dissolution of the Zn-rich matrix [15]. Therefore, it is assumed that the corrosion resistance increases with 
increase in $\mathrm{Ag}$ content. $\mathrm{Zn}-20 \mathrm{Sn}-0.50 \mathrm{Ag}$ can be assumed to have the highest corrosion resistance compared to other alloys. Thus, to improve the corrosion resistance of $\mathrm{Zn}$-based alloy, higher Ag content will be more effective.

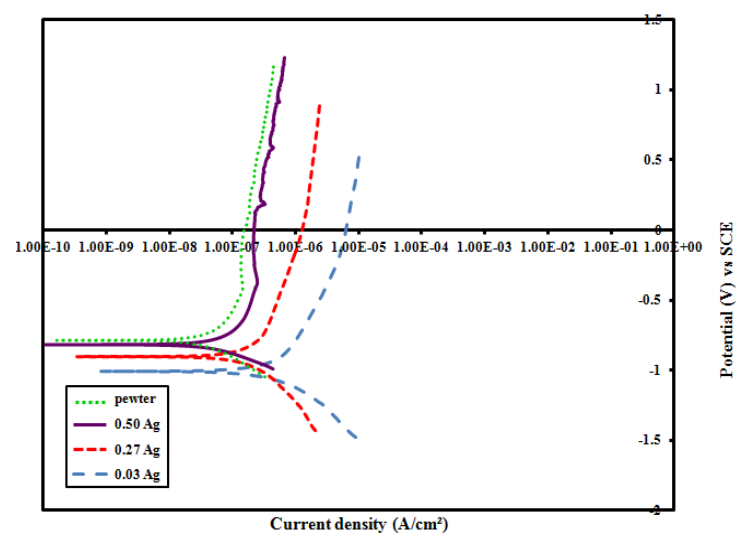

Figure 1 Polarization curves of $\mathrm{Zn}-20 \mathrm{Sn}$ with different Ag content and reference alloy tested in alkaline solution.

Fig. 2 shows the polarization curves of $\mathrm{Zn}$ $0.50 \mathrm{Ag}$ with different Sn content $(1 \%, 8 \%$ and $15 \%)$ respectively. There are distinctive passivation regions for $\mathrm{Zn}-0.50 \mathrm{Ag}-\mathrm{xSn}$ alloy, which means the passive films forming on the surface of alloys are stable and protective. It is observed that the curves of current density shift to the left side with increasing Sn content, indicating that the current density decreases with increased Sn content. The polarization curves illustrate the current density values determined from the polarization curves, showing the formation of protective passive films with $\mathrm{Sn}$ addition. $\mathrm{Zn}-0.50 \mathrm{Ag}$ with the addition of $15 \mathrm{wt} \%$ Sn shows the lowest value of current density. It has been reported that when active-passive metal was exposed to a corrosive medium and the current density of the metal was lower than about 100 $\mu \mathrm{A} / \mathrm{cm}^{2}$, the metal would spontaneously passivate [16]. On the other hand, the polarization curves in Fig. 2 illustrates that the corrosion potential increases positively with increasing $\mathrm{Sn}$ content. The corrosion resistance increases with the addition of $\mathrm{Sn}$ because the $\mathrm{Ag}_{3} \mathrm{Sn}$ appears in the $\mathrm{Zn}$ matrix [17]. Zn-0.50Ag-15Sn shows the highest corrosion potential value (Ecorr), which indicates that $\mathrm{Zn}-0.50 \mathrm{Ag}-15 \mathrm{Sn}$ is more noble and stable than $\mathrm{Zn}-0.50 \mathrm{Ag}-8 \mathrm{Sn}$ and $\mathrm{Zn}-0.50 \mathrm{Ag}-1 \mathrm{Sn}$ alloy. The $\mathrm{Zn}-0.50 \mathrm{Ag}$ alloy with $\mathrm{Sn}$ addition exhibits passive responses, indicating that the alloy surface is passivated with protective layer in the alkaline medium. Adding Sn will produce the intermetallic compound of $\mathrm{Ag}_{3} \mathrm{Sn}$. Furthermore, the compound of $\mathrm{Ag}_{3} \mathrm{Sn}$ improves the corrosion resistance of the $\mathrm{Zn}$ alloy as reported by $\mathrm{Yu}$ et. al. [18], hence the appearance of $\mathrm{Ag}_{3} \mathrm{Sn}$ and $\mathrm{Zn}$-rich phase is another important factor for the better corrosion resistance of the $\mathrm{Zn}$ alloy. This suggests that the Sn content is the major cause of the microgalvanic corrosion in the $\mathrm{Zn}$ alloys. It is assumed that the presence of $\mathrm{Ag}_{3} \mathrm{Sn}$ phase in the alloy acts as cathodic sites on the alloy surface. It is concluded that increasing Sn content will increase the corrosion resistance of $\mathrm{Zn}$ alloy and alloy with addition up to $15 \% \mathrm{Sn}$ will produce better corrosion resistance.

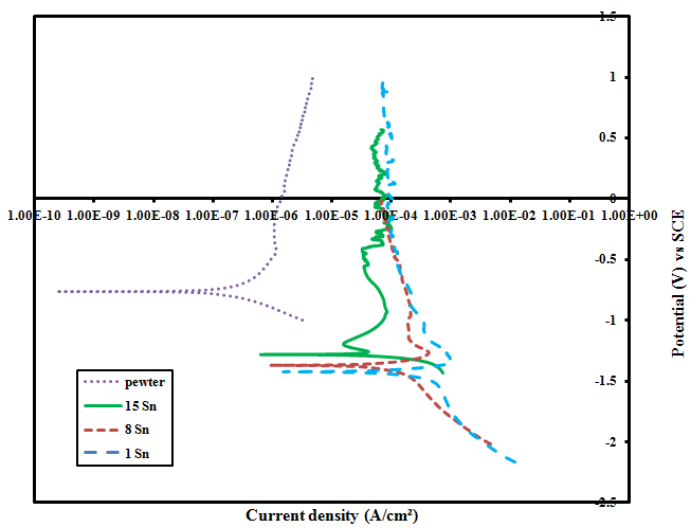

Figure 2 Polarization curves of $\mathrm{Zn}-0.50 \mathrm{Ag}$ with different $\mathrm{Sn}$ content and reference alloy tested in alkaline solution.

Table 1 summarizes the results obtained from the evaluation of the corrosion potential of the alloys. The presence of alloying element of $\mathrm{Ag}$ and $\mathrm{Sn}$ results in a displacement of the corrosion potential (Ecorr) in positive direction: $E$ corr(pewter) $>E \operatorname{corr}(0.50 \mathrm{Ag})>$ $E \operatorname{corr}(0.27 \mathrm{Ag})>E \operatorname{corr}(0.03 \mathrm{Ag})>E \operatorname{corr}(15 \mathrm{Sn})>$ $E$ corr(8Sn) $>E$ corr(1Sn). This positive shift in Ecorr is attributed to the stability and nobility of $\mathrm{Zn}$ alloy.

Table 1 Corrosion potentials obtained from Tafel polarization of the alloys in alkaline solution.

\begin{tabular}{cc}
\hline Alloy & Ecorr $($ V) vs SCE \\
\hline Pewter (reference) & -0.760 \\
Zn-20Sn-0.03Ag & -1.009 \\
Zn-20Sn-0.27Ag & -0.968 \\
Zn-20Sn-0.50Ag & -0.773 \\
Zn-0.50Ag-1Sn & -1.453 \\
Zn-0.50Ag-8Sn & -1.368 \\
Zn-0.50Ag-15Sn & -1.283 \\
\hline
\end{tabular}

Fig. 3 and 4 show the relation of corrosion current density with the corrosion rate of $\mathrm{Zn}$ alloys. The addition of $\mathrm{Ag}$ tends to lower down the corrosion rate. $\mathrm{Zn}-20 \mathrm{Sn}$ alloy with $0.50 \mathrm{Ag}$ possesses the lowest corrosion rate among others. By comparing with the reference alloy, the addition of $0.50 \mathrm{wt} \% \mathrm{Ag}$ reduces the corrosion rate by $10 \%$. In addition, the $\mathrm{Zn}-20 \mathrm{Sn}$ with the addition of $0.50 \mathrm{Ag}$ shows an activity close to Pewter. 
Secondly, as the $\mathrm{Sn}$ content is higher, passive phenomena are clearly found as the potentials are more positive than their corresponding Ecorr. Moreover, the corrosion rate is decreasing by raising the Sn content, and $\mathrm{Zn}-0.50 \mathrm{Ag}-15 \mathrm{Sn}$ shows the lowest corrosion rate. In addition, the lower current density values indicate that the rate of dissolution is lower and better anticorrosive ability of alloy for the attack of $\mathrm{OH}^{-}$. Based on the results, by comparing both $\mathrm{Zn}$ alloy with $15 \mathrm{wt} \% \mathrm{Sn}$ and $0.50 \mathrm{wt} \% \mathrm{Ag}$, the best anticorrosive material should be the $\mathrm{Zn}-20 \mathrm{Sn}$ alloy with $0.50 \mathrm{wt} \% \mathrm{Ag}$. In general, a small corrosion current density (Icorr) value indicates a lower corrosion rate while a higher current density (Icorr) signifies higher corrosion rate.

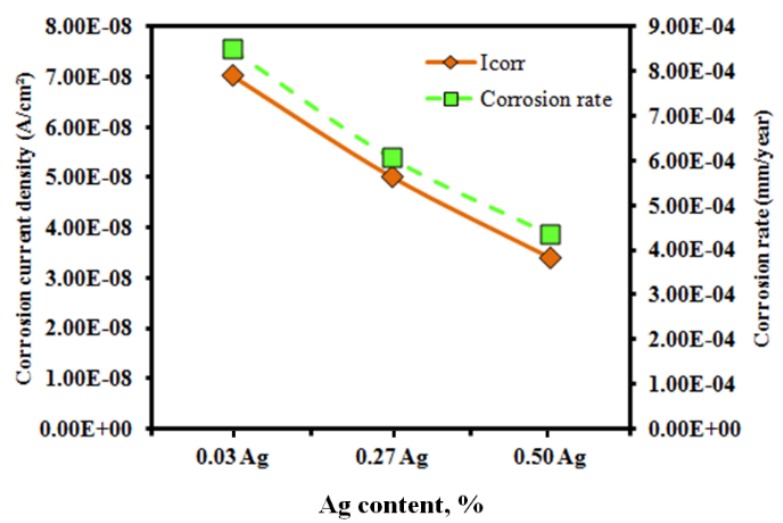

Figure 3 The corrosion current density and corrosion rate of $\mathrm{Zn}-20 \mathrm{Sn}$ with different $\mathrm{Ag}$ content tested in alkali.

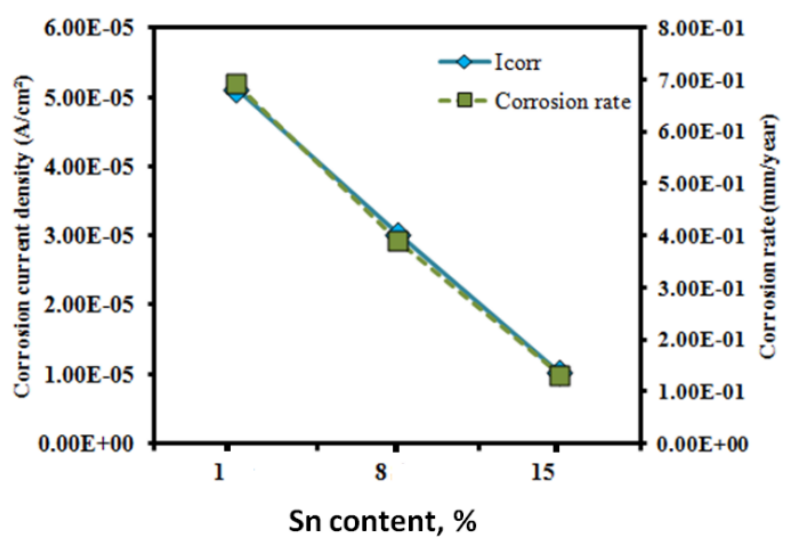

Figure 4 The corrosion current density and corrosion rate of $\mathrm{Zn}-0.50 \mathrm{Ag}$ with different Sn content tested in alkali.

Several studies on the corrosion behavior of zinc in alkaline solutions have been carried out, whereby the corrosion of zinc proceeds via two partial reactions: The cathodic reaction corresponds to the reduction of oxygen [19].

$$
\mathrm{O}_{2}(g)+2 \mathrm{H}_{2} \mathrm{O}+4 e^{-} \rightarrow 4 \mathrm{OH}^{-}
$$

The anodic reaction involves the dissolution of zinc and leads to weight loss [20,21].

$$
Z n \rightarrow Z n^{2+}+2 e^{-}
$$

In the cathodic polarization curves, characteristic behavior of processes controlled purely by diffusion. This process is associated with the reduction of oxygen in the electrolyte (alkaline) solution [22]. The anodic polarization curves exhibit an active/passive transition. In the active region, the dissolution current increases linearly with the applied potential then followed by the appearance of peak, which can be associated with the active dissolution of $\mathrm{Zn}$ to $\mathrm{Zn}$ (II) species according to reaction (2) and:

$$
\mathrm{Zn}^{2+}+2 \mathrm{OH}^{-} \rightarrow \mathrm{Zn}(\mathrm{OH})_{2}
$$

While small anodic peak appears may be related to the dehydration of $\mathrm{Zn}(\mathrm{OH})_{2}$ to $\mathrm{ZnO}$ as the following reaction:

$$
\mathrm{Zn}(\mathrm{OH})_{2} \rightarrow \mathrm{ZnO}+\mathrm{H}_{2} \mathrm{O}
$$

After the formation of $\mathrm{ZnO}$ on the alloy surface, $\mathrm{Zn}(\mathrm{OH})_{2}$ or $\mathrm{ZnO}$ dissolves by the reaction with further hydroxide to form zincates ion $\left[\mathrm{Zn}(\mathrm{OH})_{4}\right]^{2-}$ according to [23]:

$$
\begin{gathered}
\mathrm{Zn}(\mathrm{OH})_{2}+2 \mathrm{OH}^{-} \rightarrow\left[\mathrm{Zn}(\mathrm{OH})_{4}\right]^{2-} \\
\text { Or } \\
\mathrm{ZnO}+\mathrm{H}_{2} \mathrm{O}+2 \mathrm{OH}^{-} \rightarrow\left[\mathrm{Zn}(\mathrm{OH})_{4}\right]^{2-}
\end{gathered}
$$

When the electrolyte in the immediate vicinity of the alloy becomes supersaturated with $\left[\mathrm{Zn}(\mathrm{OH})_{4}\right]^{2-}$, $\mathrm{Zn}(\mathrm{OH})_{2}$ precipitates on $\mathrm{Zn}$ surface to form a porous or nodular film. Dissolution proceeds according to the reaction (5) and (6) until the $\mathrm{ZnO}$ is insoluble. At this stage, the alloy surface is passivated because of the surface formation of a thin compact $\mathrm{ZnO}$ layer. It is well known that an oxide or hydrated oxide is formed on zinc when immersed in alkaline solution of $\mathrm{NaOH}$. These insoluble zinc salts $\left(\mathrm{ZnO}\right.$ or $\left.\mathrm{Zn}(\mathrm{OH})_{2}\right)$ cover the surface of the corroded zinc.

\section{Elemental Composition of Corrosion Product}

The passive layer formed on the surface of $\mathrm{Zn}$ alloys with $\mathrm{Ag}$ and $\mathrm{Sn}$ addition after anodic polarization treatment in alkaline solution. The passive electrode was withdrawn carefully, washed with distilled water, dried and finally examined by XRD.

Fig. 5 represents the XRD of passive layer formed on the surface of $\mathrm{Zn}-20 \mathrm{Sn}$ with Ag addition. The data confirm the existence of $\mathrm{Zn}$ as a major, but $\mathrm{ZnO}$ or 
$\mathrm{Zn}(\mathrm{OH})_{2}$ as a minor constituents. Presence of Sn and $\mathrm{Ag}_{3} \mathrm{Sn}$ phases were identified with the increased in $\mathrm{Ag}$ content. Moreover, these results also indicate that the peak potential of $\mathrm{Zn}$ in alkaline solution is related to the formation of $\mathrm{ZnO}$ and $\mathrm{Zn}(\mathrm{OH})_{2}$ system on the electrode surface. Comparison between X-ray data for the presence $\mathrm{ZnO}$ and $\mathrm{Zn}(\mathrm{OH})_{2}$ amounts on the surface of the alloys reveals that a large amount of $\mathrm{ZnO}$ or $\mathrm{Zn}(\mathrm{OH})_{2}$ is formed at low current density compared with those amounts formed at high current density. This provides that at high current density (Zn-20Sn-0.27Ag and Zn$20 \mathrm{Sn}-0.03 \mathrm{Ag}$ ), most $\mathrm{ZnO}$ dissolves in alkaline solution and leads to reactivation of the electrode surface. Therefore, XRD results are in good agreement with polarization measurements, which indicate that the $\mathrm{Ag}$ addition retards the formation of $\mathrm{ZnO}$ and $\mathrm{Zn}(\mathrm{OH})_{2}$ by the presence of $\mathrm{Ag}_{3} \mathrm{Sn}$ phase.
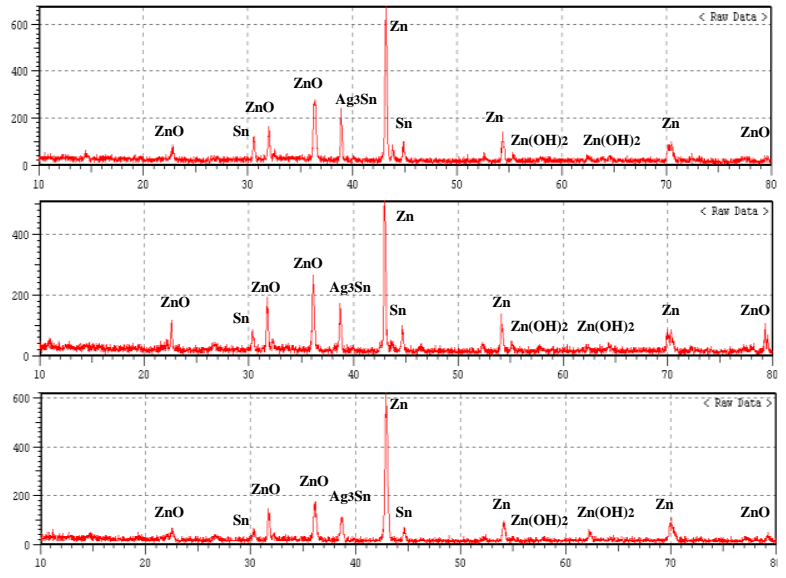

Figure $5 \mathrm{X}$-ray diffraction patterns for the passive film of $\mathrm{Zn}$ 20Sn with Ag addition.

Fig. 6 shows the XRD pattern of $\mathrm{Zn}-0.50 \mathrm{Ag}$ alloy with Sn addition treated in alkaline solution, in which $\mathrm{Zn}$ rich phase, $\mathrm{Sn}$ rich phase and a small quantity of $\mathrm{Ag}_{3} \mathrm{Sn}$ compounds are identified. The data reveal that the surface contains only a small amounts of $\mathrm{ZnO}$. This confirms that it may be attributed to the trend of polarization curve with low passivation occur. This trend also may be attributed to the direct oxidation of $\mathrm{Zn}$ to $\mathrm{ZnO}$. It has been reported that the alloy composed of $\mathrm{Sn}$ dispersing in $\mathrm{Zn}$ matrix because $\mathrm{Sn}$ has a very low solubility in $\mathrm{Zn}$. When $\mathrm{Sn}$ segregates, it reacts with $\mathrm{Ag}$ to form the compounds of $\mathrm{Ag}_{3} \mathrm{Sn}$ and induce the corrosion [24,25]. Therefore, the presence of $\mathrm{Ag}_{3} \mathrm{Sn}$ reduces corrosion by adding $\mathrm{Sn}$.
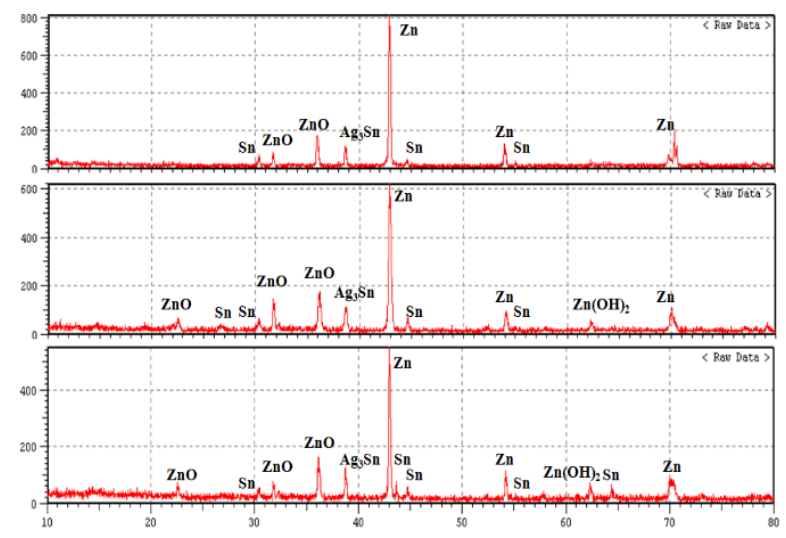

Figure $6 \mathrm{X}$-ray diffraction patterns for the passive film of $\mathrm{Zn}$ $0.50 \mathrm{Ag}$ with $\mathrm{Sn}$ addition.

In conclusion, the main corrosion products formed on the $\mathrm{Zn}$ alloy surface treated in alkaline solution are $\mathrm{ZnO}$ and $\mathrm{Zn}(\mathrm{OH})_{2}$.

\section{Surface Morphology}

Fig. 7 shows the micrographs of the anodic passive film formed on the surface of Zn-20Sn alloys with different content of $\mathrm{Ag}$ in alkaline solution with magnification of $1000 \mathrm{X}$. Some typical images clearly revealed that the $\mathrm{Zn}$ alloy surface is well covered by a layer of corrosion products. Fig. 7a shows SEM micrographs of $\mathrm{Zn}-20 \mathrm{Sn}-0.50 \mathrm{Ag}$ alloy. It is observed that the surface is almost completely covered by adhered passive oxides. Two layers are observed on the electrode surface. The crystals of the upper layer exhibit different shapes and partially cover the underneath surface by smaller nodular crystals compared with those observed in Fig. $7 \mathrm{~b}$ and $7 \mathrm{c}$. The second layer seems to lie below the upper layer and their crystals sizes are bigger. The upper layer might be related to $\mathrm{AgSn}$, while the underneath layer is due to $\mathrm{ZnO} / \mathrm{Zn}(\mathrm{OH})_{2}$ formation. This indicates that the presence of $\mathrm{Ag}$ as alloying element retards the formation of $\mathrm{ZnO}$ and $\mathrm{Zn}(\mathrm{OH})_{2}$ on the alloy surface.
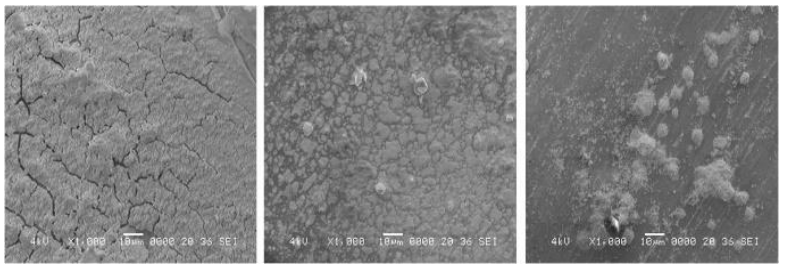

Figure 7 SEM micrographs of passive film formed anodically in alkaline solution on the $\mathrm{Zn}$-20Sn surface with the addition of (a) $0.50 \mathrm{Ag}$ (b) $0.27 \mathrm{Ag}$ (c) $0.03 \mathrm{Ag}$.

For the $\mathrm{Zn}-20 \mathrm{Sn}-0.27 \mathrm{Ag}$ electrode surface in Fig. $7 b$, a layer of the oxide crystals appeared on the alloy surface. It was observed that the nodular product 
on the upper layer vanished while the amount of the crystals at the underneath layer decreased and became more distant apart than those in Fig. 7a. The quantity of the oxide crystals in the underneath layer decreases with smaller size. Whereas the crystals of the layer become loosely bound to the alloy surface and an amount from this layer dissolves in the bulk of solution. In addition, the crystals of the underneath layer are distorted. This observation may be attributed to the partially dissolving ability of $\mathrm{OH}^{-}$ions on the crystal of the oxides film.

It would be recognized in Fig. $7 \mathrm{c}$ that the oxide film formed on treated $\mathrm{Zn}-20 \mathrm{Sn}-0.03 \mathrm{Ag}$ alloy surface is less than that formed at more positive potential (Fig. 7a and $7 \mathrm{~b}$ ). The treated surface is not partially covered by the passive layer so that the electrode surface can still be seen. The nodular oxide crystals exhibit different shapes and become smaller compared with those $\mathrm{Zn}$ alloys in Fig. 7a and 7b. Therefore, the addition of $0.50 \mathrm{Ag}$ in $\mathrm{Zn}$ 20Sn will produce the passivation layer that will stop the corrosion activity.
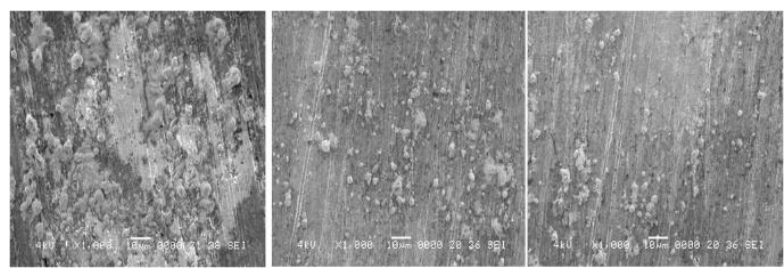

Figure 8 SEM micrographs of passive film formed anodically in alkaline solution on the $\mathrm{Zn}-0.50 \mathrm{Ag}$ surface with the addition of (a) $15 \mathrm{Sn}$ (b) $8 \mathrm{Sn}$ (c) $1 \mathrm{Sn}$.

Fig. 8 shows the micrographs of the anodic passive films formed on the surface of $\mathrm{Zn}-0.50 \mathrm{Ag}$ alloys with the addition of 1,8 and $15 \mathrm{Sn}$ in alkaline solution at passive region with a magnification of $1000 \mathrm{X}$. It may appear from Fig. 8a that the surface of Zn-0.50Ag-15Sn is almost completely covered by thick nodular layer of corrosion product and loosely bound to the metal surface. In addition, the attack begins at the surface defects which are in the polishing scratch. The crystals of this layer exhibit different shapes that might related to the mixture of $\mathrm{ZnO}$ and $\mathrm{Zn}(\mathrm{OH})_{2}$. However, the photograph of $\mathrm{Zn}-0.50 \mathrm{Ag}-8 \mathrm{Sn}$ treated anodically shown in Fig. 8b shows that the crystal size is smaller than that at less positive potential, while for $\mathrm{Zn}-0.50 \mathrm{Ag}-1 \mathrm{Sn}$, the crystal size is the smallest and lesser than other alloys when the potential is the lowest. The crystals of the layer become more adhered on the surface and not compact. Thus most parts of the alloy surface show more empty space. This is the reason why the potential curve did not show the passivation curve. Therefore SEM results support the measurements; the addition of Sn enhances passivation activity.

The results shown in Fig. 7 and 8 indicate the differences in the morphology developed on the surface of the $\mathrm{Zn}$ alloy with the addition of $\mathrm{Ag}$ and Sn. It seems that the coverage and the morphology developed on the $\mathrm{Zn}$ alloy surface with the addition of $\mathrm{Ag}$ is preferable, supporting the electrochemical studies indicating that the addition of $\mathrm{Ag}$ is superior in reducing the corrosion rate of the $\mathrm{Zn}$ alloy and induce the passivation.

\section{CONCLUSION}

Corrosion behavior of zinc alloy with the addition of silver and tin has been investigated experimentally. The Zn-20Sn-0.50Ag alloy exhibited good anti-corrosive properties in alkaline medium. The addition of $\mathrm{Ag}$ shifted the anodic and cathodic branches to lower currents densities and corrosion potential (Ecorr) to more noble values compared to $\mathrm{Sn}$ addition. The corrosion rate of zinc alloy with $\mathrm{Ag}$ addition is reducing to lower value that resulted in better corrosion resistance. The presence of corrosion products, $\mathrm{ZnO}$ and $\mathrm{Zn}(\mathrm{OH})_{2}$ reduced with increasing $\mathrm{Ag}$ and $\mathrm{Sn}$. The passive films of the passivated surface are presence on the alloy with lower corrosion rate.

\section{ACKNOWLEDGMENTS}

The authors acknowledge the financial support from Kulliyah of Engineering, International Islamic University Malaysia and Royal Selangor International Sdn. Bhd. for their support of this research.

\section{REFERENCES}

[1] M.McCormack and S.Jin: JOM. 45 (1993) 36-40.

[2] K. Sugunuma, K. Niihara, T. Shoutoku and Y. Nakamura: J. Mater. Res. 13 (1998) 2859-2865.

[3] J.M. Song and Z.M. Wu: Scr. Mater. 54 (2006) 14791483.

[4] S.C. Cheng and K.L. Lin: Mater. Trans. 46 (2005) 42-47.

[5] T. Takenomoto and T. Funaki: Mater. Trans. 4 (2002) 1784-1790.

[6] E.M.L. Valeriote, A. Heim and M.S. Ho: J. Power Sources. 33 (1991)187-212.

[7] M. Mori, K. Miura, T. Sasaki and T Ohtsuka: Corros Sci. 44 (2002) 887-898.

[8] H.R. Thirsk, R. D. Armstrong and M.F. Bell: Electrochemistry, 4 (1994) 1-17.

[9] R. Tremont, H. De Jesus-Cardona, J. Garcia-Orozro, R.J. Castro and C.R. Cabrera: J. Appl. Electrochem. 30 (2000) 737-743.

[10] J. W. Schultze and K. Wippermann: Electrochim. Acta. 32 (1987) 823-831.

[11] L. Dezhi, P. C. Paul and L. Changqing: Corros. Sci. 50 (2008) 995-1004.

[12] F. Song and S. W. R. Lee: Electronic Components and Technology Conference (2006) pp. 891-898.

[13] M. Mori, K. Miura, T. Sasaki and T. Ohtska: Corros. Sci., 44 (2002) 887-898. 
[14] T.DC. Chang, M.H. Hon, M.C. Wang and D.Y. Lin: J. Electrochem. Soc. 151 (2004) C484-C491.

[15] G. Montesperelli, M. Rapone, F. Nanni, P. Travaglia, P. Riani, R. Marazza and G. Gusmano: Mater. Corros. 59 (2008) 662.

[16] B.Guo, Y.X. Tong, F. Chen, Y. F. Zheng, L.Li and C. Y. Chung: Mater Corros. 63 (2012) 259-263.

[17] T.C. Chang, M.H. Hon and M.C. Wang: J. Alloy Compd. 402 (2005) 141-148.

[18] S.P. Yu, C.L. Liao, M.C. Wang and M.H. Hon: J. Mater. Sci. 35 (2001), 4217-4224.

[19] Q. Qu, L. Li, W. Bai, C. Yan, and C.N. Cao: Corros. Sci. 47 (2005) 2832-2840.

[20] N. Boshkov, N. Tsvetkova, P.Petrov, D. Koleva, K. Petrov, G. Avdeev, C. Tsvetanov, G.
Raichevsky and R. Raiceff: Appl Surf Sci. 254 (2008) 5618-5625.

[21] M. Geary and C.B. Breslin: Corros. Sci. 39 (1997) 1341-1350.

[22] Mars G. Fontana: Corrosion Engineering, (McGraw-Hill International Editions, 1987) pp. 230-231

[23] A.R. El-Sayed, S.H. Mohran and H. M. A. ElLateef: J Power Sources, 195 (2010) 6924-6936.

[24] Y.D. Tsai and C. C. Hu: J. Electrochem. Soc. 158 (2011) D527-D534.

[25] C.T. Lynch: CRC Handbook of Materials Science II, (CRC Press Inc., Boca Raton, USA, 1974) p. 399. 